\title{
Unpacking challenges in student-faculty partnerships on Departmental Action Teams
}

\author{
Gina M. Quan \\ Department of Physics \& Astronomy, San José State University, San José, CA, 95192-0106 \\ Joel C. Corbo and Sarah Wise \\ Center for STEM Learning, University of Colorado Boulder, Boulder, CO, 80309 \\ Courtney Ngai \\ The Institute for Learning and Teaching, Colorado State University, Fort Collins, CO, 80523
}

This paper is a case study analysis of one student-faculty partnership working to enact departmental change. Students as Partners $(\mathrm{SaP})$ is an approach in which students and faculty work in partnership on the co-design of a curricular or institutional change effort. Our team implements SaP through Departmental Action Teams (DATs), which are facilitated teams of faculty, students, and staff within a single STEM department working on an issue related to undergraduate education. In our research, we aim to understand the ways in which SaP becomes enacted in DATs. Through analyzing interviews with student and faculty members of a single DAT, we construct a case study of the complexities and challenges of student-faculty partnership. We find that members of a partnership can hold different views of that partnership. Underlying these differences are differing views about their joint work as well as differences in the visibility of power dynamics. In self-critically analyzing the ways in which we mitigated and reproduced power dynamics, we reflect on our project's areas for growth. 
Students as Partners ( $\mathrm{SaP})$ has been gaining traction as an approach to curricular design (e.g., [1]), teaching (e.g., $[2,3]$ ) and institutional change efforts (e.g., [4]). While it is typical for faculty and staff to make decisions about education for students, $\mathrm{SaP}$ is an approach in which faculty and staff make decisions with students. Implementations vary in the scope of student involvement and the amount of power shared, depending on what is appropriate for the context [5]. The SaP literature has documented numerous positive outcomes of SaP, including more successful innovations, improved faculty-student relationships, and even student learning and attitudinal shifts [6]. More recently, research has also begun to document the challenges that can emerge in studentfaculty partnerships, particularly as such partnerships contend with power dynamics that exist in higher education [1, 7]. This paper furthers this work by constructing a case study of the complexities of one student-faculty partnership.

\section{STUDENTS AS PARTNERS ON DEPARTMENTAL ACTION TEAMS}

We consider $\mathrm{SaP}$ in the context of students and faculty working together to implement departmental changes. Departmental Action Teams (DATs) are teams of faculty, students, and staff working together to address an educational issue within their department. External facilitators support DAT members toward creating change around a broad educational issue and help DAT members develop change agency and leadership skills. The authors of this paper have all contributed to developing the DAT model, facilitating DATs, and conducting research on the DAT model in seventeen departments at two different universities (e.g., [4, 8-10]). In prior work, we have articulated our model's Core Principles which serve as the design principles for our model [4].

In this paper, we zoom in on Principle 1, students are partners in the educational process. Our conceptual understanding of this principle involves the following components:

- Students have unique expertise $[2,11]$.

- The group seeks diverse student perspectives on an ongoing basis [12].

- Students and faculty share power and decision making $[5,6]$.

- Students see themselves as partners [6].

DAT members are made aware of these principles throughout their work. In alignment with this principle, we encourage DATs to include student members and we normalize student participation through offering student stipends. Facilitators support student participants through monitoring the relative talk time of DAT members, revoicing student contributions, and teaching consensus-based decision making structures. Similar to other instantiations of SaP, we find that this principle positively impacts the success of DATs [4]. We also find it necessary to critically reflect on our implementation of the principle to understand our areas for growth. Aligned with calls for more self-critical SaP work [1] as well as calls for deeper theorizing about power in partnerships [13], we move beyond the binary question of "are students partners" to asking "in what ways are students partners and in what ways are they not?" In this paper, we present the experience of one DAT as a case study of the complexities of student-faculty partnerships.

\section{ANALYTICAL APPROACH AND CONTEXT}

As part of ongoing research on the DAT model, we have been studying how and the extent to which Core Principles become embodied in DAT work. This paper focuses on segments of interview data related to the students as partners principle. Interview questions invited DAT members to discuss their experiences on the DAT (e.g., "Do you feel like there are power differences on the DAT?," "Do you think that differences in participants' roles within the department have impacted the DAT? If so, how?") and to reflect on the Core Principles (e.g., "Thinking about your work in the DAT, how do these apply?"). Our analytical process began by "chunking" interview transcripts and noting which segments discussed any of the components of students as partners described above. From these segments, we engaged in a process of tagging data and developing analytic memos in order to progressively identify themes [14]. We then decided to focus on three interviewees from a single DAT, in order to compare perspectives of different members. Our analysis of these three perspectives draws from the practice of crystallization [15], which assumes that participants' different viewpoints lead to different accounts of their partnership (like facets of a crystal). We start from the assumption that all of these perspectives can be "true," even when they disagree.

TABLE I. Membership of Focal DAT by Semester

\begin{tabular}{l|l}
\hline \hline Semester & Members \\
\hline Fall (Y1) & 6 faculty \\
Spring (Y1) & 5 faculty, 1 grad student, 1 undergrad student \\
Summer (Y1) & 5 faculty, 4 grad students, 1 undergrad student \\
Fall (Y2) & 5 faculty, 3 grad students \\
Spring (Y2) & 5 faculty, 3 grad students \\
\hline
\end{tabular}

This paper draws on interviews of three DAT members: Drew (an undergraduate student), Gemma (a graduate student) and Franklin (a faculty member). Over two years (Table 1 ), the case study DAT included seven faculty members, four graduate students, one undergraduate student, and no staff. The focus of the DAT was to develop an understanding of how discipline-specific skills were developed throughout the majors sequence. The DAT started in Fall (Y1) and consisted of only faculty members, including Franklin. In Spring (Y1), two students, Gemma and Drew, were invited to join the DAT based on their prior interest in education. The DAT secured stipends for three more graduate students to join in Summer 
(Y1). Due to summer commitments, most faculty (including Franklin) only participated sporadically during Summer (Y1). Interviews with Drew, Gemma, and Franklin were conducted in Fall (Y2).

The DAT was successful in many ways. After two years of facilitation, the DAT had developed several tools for assessing disciplinary skills and institutionalized an assessment plan with broad departmental support. Students and faculty noted that students participated meaningfully in the DAT activities. At the same time, interviews point to divergent perspectives on how the DAT enacted SaP. Using this data, we discuss how members' perspectives on a partnership differ. We then unpack how these perspectives are tied to attention to different aspects of their joint work, as well as the differences in how each member noticed the power dynamics present.

\section{MEMBERS OF A PARTNERSHIP CAN HOLD DIFFERENT PERSPECTIVES ABOUT THE PARTNERSHIP}

We found similarities and differences in how Drew, Gemma, and Franklin described the student-faculty partnership on the DAT. When asked to describe DAT meetings, Gemma (graduate student) describes the evolution of the relationship between students and faculty on the DAT as they increased the number of graduate student members:

Since adding more graduate students, it feels like some of the faculty have started to slip back to "I'm faculty and you're a student" instead of "we're collaborators" mode. I've seen faculty delegating tasks down to the students more than they delegate to each other, and also being a little bit more resistant when students challenge them, versus when it was just me I think it was easier to just be like "oh she's one of us, it's fine." But when there are more of us...they become more aware, either consciously or unconsciously, of the student-faculty divide, which kind of sucks, because I don't like being the only grad student as much. It would have been good to have peers. But I also don't like that I see faculty sometimes drifting away from the equal committee member model.

In the quote above, Gemma describes how the DAT initially felt less hierarchical, which she calls the "collaborators mode" and "equal committee member model." After the transition, Gemma describes some faculty members adopting a more hierarchical way of interacting, which she attributes to the increased number of students. Gemma perceives there being a tradeoff between being the lone graduate student and cueing up the "student" role. In addition to the increased number of graduate students, we suspect that other contextual factors played a role in this shift. Because the DAT secured funding for the additional student members, the DAT faculty members might have seen the relationship with the students as more transactional. The students were the only continuous members of the DAT during the summer and took on the majority of the work from then on. It is unclear from our data how these factors informed Gemma's perspective.

Gemma's interview describes the partnership feeling more collaborative in Spring (Y1) and hierarchical in Summer (Y1). On the other hand, Drew (undergraduate student) described the partnership becoming increasingly easier for them. Drew did perceive differences in roles at first:

\begin{abstract}
I have a very unique perspective as the only undergrad because I felt a little out of place. It was very strange to be there, because it was a bunch of $\mathrm{PhD}$ students, more than halfway done, and then all these tenured professors, and I'm sitting here like I can contribute, possibly, maybe? ... By the end of the semester it was much easier. ...It was just sort of my own questioning, like do I really belong here? What am I doing here?
\end{abstract}

To Drew, the presence of faculty and graduate students was salient at the start, as they worried about their ability to contribute. Drew says that it became easier for them by the end of the semester, which happened to be when Gemma felt like the hierarchies were becoming more salient.

Franklin (faculty) did not bring up faculty-student hierarchy, but did speak to the role of students on the DAT. When asked to describe what it was like to have faculty and students on the same group, Franklin said:

I think that the undergraduate student presence has kind of tailed off for whatever reason. But the graduate student presence has grown... Those that have been involved are really enthusiastic about it, they have really good ideas, fresh ideas, perspectives, and they're just really productive. It's been really enlightening and refreshing and enjoyable to see how motivated they are... my impression is that their research, their main academic work for their degree, hasn't suffered, so I think that it's been nothing but good for them.

Franklin has little to say about the undergraduate student participation other than that it had "tailed off"-likely because Drew had to step back from the DAT at the end of Summer (Y1). He does see the growth in graduate student membership as being a positive aspect of the DAT. He does not express any concerns about the faculty-student partnership, instead citing the graduate students' enthusiasm, ideas, and productivity as positive for the DAT and "nothing but good for them." In this quote, his description of students on the DAT does not explicitly address hierarchy (or a lack thereof).

Together these segments show how individuals' perspectives on partnerships can differ. In the next two sections, we explore two factors underlying these differences: (1) attention to different aspects of their work and (2) differences in the visibility of power dynamics to different members. 


\section{MEMBERS ATTEND TO DIFFERENT ASPECTS OF THEIR WORK WHEN THINKING ABOUT PARTNERSHIP}

One underlying difference in how participants viewed partnership was attention to different aspects of the DAT's work. In the previous quote from Gemma, she distinguished between "collaborator" mode versus "faculty/student" mode. She characterized the latter as involving "delegating down" and being "resistant to challenges." She elaborated:

When faculty sit back and they're like, "well, I don't know, what do you want to do? What do you want to do? What do you want to do?" And sort of make the students make all the decisions implicitly that way, it doesn't feel very productive. It feels kind of masked, like "look how empowered you are!" But instead it's like "look how much work you can do instead of me"... The exception to that is Laura. I think she 100 percent is still treating all the students as equals... She volunteers to do the grunt work, she doesn't complain when grad students challenge her.

Gemma describes how leaving decisions up to students may be seen as "empowered" but feels overburdening to students who have to assume that responsibility. In this interview, Gemma does not elaborate on the types of decisions that felt overburdening to her, but the graduate students did have significant responsibility in developing the activities for their DAT. She uses one faculty member as a contrast (Laura) who does "grunt work" and "doesn't complain when grad students challenge her." This reinforces our interpretation that the most important signifiers of partnership to Gemma are who is taking on "grunt work" and how faculty react to being challenged. We note that what is important to Gemma is the process of how work gets done; she does not feel like she has a say in deciding who decides.

On the other hand, Franklin (faculty) does not describe these power dynamics:

Franklin: Our team includes faculty and graduate students, and that's another thing that I think many of us didn't foresee but has been amazingly productive and encouraging, is the role of the graduate students...sometimes there are just graduate students that are doing things on their own outside of the DAT meetings, sometimes there are a couple of really dedicated faculty that do a lot... they're doing lots of things outside of the normal biweekly DAT meetings.

Interviewer: Do you feel like there are power differences on the DAT having the two different roles on the team?

Franklin: No. No, I mean the graduate students that are involved are confident enough to speak up. They're just as opinionated as anybody else in the room. I don't think that there's any intimidation or anything like that. The faculty members I think are all of the appropriate personality that there's no real danger of that. It hasn't really always been the case, but I don't think it's an issue at all now.

We see some agreement between Franklin and Gemma about how the DAT functions-graduate students and some faculty take on extra work in subgroups. Franklin refers to those faculty as "really dedicated," suggesting that taking on extra work was not an expectation for faculty. Franklin sees graduate student participation as productive and encouraging, whereas Gemma was frustrated by the imbalanced workload. To Franklin, students speaking up and sharing opinions demonstrates a lack of power differences. He highlights how it "hasn't always been the case," likely referencing early interactions in the DAT when there was one dominating faculty member (who later stopped participating). We notice that Franklin is focused on whether students share opinions but not on how faculty respond to that sharing.

Both Franklin and Gemma were attentive to the process of how work gets done when evaluating their partnership, but they focused on different aspects of the process. On the other hand, our previous quote from Drew focuses on the content of the work. Their question, "can I contribute, possibly, maybe?" suggests that they are more attentive to the expertise that each member brings rather than the process of getting the work done. This is reinforced later on in the interview when Drew elaborated on the expertise of each role:

The faculty acted as group leaders a lot of the time... They led stuff and sort of delegated from their role and did all the faculty outreach. The grad students were the next tier down. They did a lot of the heavy grunt work that would require some expertise. ...I was there to give that [undergrad] perspective and I was there to reach out to undergraduates... Because I'm their friends, like they know me. So I felt like while the faculty did faculty outreach, I was there to do undergrad outreach...

Drew described the roles in terms of "tiers"-suggesting they perceived this difference as hierarchical. They mention that graduate students did "grunt work," which is consistent with Gemma's and Franklin's accounts that graduate students took on more work than others. At the same time, Drew frames this division as being due to each group's ability to contribute a different form of expertise and doesn't question the process as Gemma does.

\section{POWER DYNAMICS ARE MORE AND LESS VISIBLE DEPENDING ON ROLES}

Finally, we also noticed how power dynamics were more and less visible (and acceptable) to DAT members depending on their roles. As we saw previously, Franklin did not identify any power differentials, whereas Drew and Gemma both did. In reflecting on Principle 1, Drew elaborated on 
how these roles felt inevitable:

Students are partners...it's really important, and I feel that faculty and everyone definitely tries, but of course it's difficult to uphold in reality simply because students are in a different level of their life...I'm a literal student who is a literal partner in the DAT. Yes I was a partner, but it definitely wasn't an equal share. I wasn't doing the same amount or same caliber of work as the grad students, and the grad students weren't doing the same thing as the faculty. I mean there's a natural hierarchy in academia where students are partners but not equal share. So that one might be a little misleading, simply because partners always implies a 50-50 share and I don't think it is.

To Drew, partnership means an equal division of labor, and they specifically say they aren't in a "50-50" partnership because they lack expertise. On the other hand, the SaP literature emphasizes reciprocity-the ability for both parties to contribute and benefit-as characterizing successful partnership [6].

Drew uses the word "natural" to describe an unequal division of labor and hierarchy. In contrast, Gemma sees the hierarchy as a habit that could be broken:

I think it's just habit. We are students, and in all other contexts it's totally fine to delegate down to us... it's tricky because the students don't want to be taking on a huge amount of extra leadership and extra work, they just want to be equal committee members... if there was really explicit discussion about this was productive because your students were your partners, all of this work was done, you were feeding off of each other, it was not a chain of command. I think we had a process skill that was about network style leadership instead of hierarchical leadership. Reiterating that, I think that would be fine.

In the above quote, Gemma says that the power dynamics are "a habit" due to the more common ways faculty and students interact. She sees this dynamic as changeable, but one that requires active effort to do something different from the norm. She cites one "process skill" - an activity led by the facilitators discussing the implications of flat versus hierarchical leadership models - as something that may help the group shift back.

As we see, members can perceive the partnership differently. Franklin stated that he did not notice power dynamics, but was mainly focused on whether students were sharing ideas. Gemma did see power dynamics emerge as more students were included but was critical of power dynamics; she noted the unequal division of responsibilities and lack of say in the process as things that could be changed. Drew described the hierarchical relationship as natural, but spoke to the different forms of expertise that each member contributed.

\section{DISCUSSION}

In this case study, we illustrate multifaceted perspectives on student-faculty partnerships to help both the readers and ourselves grow toward enacting more equitable partnerships. While our project is working toward less hierarchical partnerships, this work helps us refine our own conceptualization of SaP. This will help our project better understand for ourselves which forms of $\mathrm{SaP}$ to strive for in DATs. We align with Gemma's perspective that hierarchy is changeable, but it requires work to do so.

When looking for indicators of student-faculty partnership, it is important to not only consider who contributes but also how responsibilities are divided. Students taking on the majority of responsibilities is a sign of uneven partnership. Relatedly, it is also important to consider who is deciding who decides; do students contribute to decisions about process or are faculty determining that process? Finally, it is important to consider how roles and hierarchies can emerge in discussions, including how to minimize their negative impacts. Looking at microgenetic analyses of emergent power dynamics [1] may provide some tools for noticing these.

We emphasize the need for critical self-reflection. We note that both DAT participants and facilitators viewed the DAT as a positive example of students as partners. As our work is principles-driven, collecting data and identifying areas for growth is critical for us to do better in the future. We invite readers to consider whose voices are included when we reflect on a "partnership." As we show, what looks like a partnership to one person may not feel like partnership to another. If we privilege the gaze of facilitators or faculty, we miss out on key perspectives from students.

Such self-reflective work also invites us to ask ourselves what we are striving toward in enacting "partnership." As we see above, DAT members attend to a multiplicity of features when evaluating partnership-ability to contribute ideas, ability to contribute to process, voicing opinions, having those opinions heard. And there are differences in the extent to which asymmetries in contributions are critiqued versus taken as given. We suspect that these visions for partnership are bounded by the kinds of interactions participants even imagine is possible. We suggest that an outcome of the DAT project is not only helping groups achieve departmental change, but also pushing the boundaries of the kinds of student-faculty relationships that DAT participants can imagine, and therefore enact.

\section{ACKNOWLEDGMENTS}

We thank members of the DAT project team for their contributions to this work. This material is based upon work supported by the National Science Foundation under Grant No. 1626565 . 
[1] E. R. Sohr, A. Gupta, B. J. Johnson, and G. M. Quan, Physical Review Physics Education Research 16, 020157 (2020).

[2] M. S. Sabella, A. G. Van Duzor, and F. Davenport, in 2016 Physics Education Research Conference Proceedings (2016).

[3] H. E. Jardine, International Journal for Students as Partners 4, 48 (2020).

[4] G. M. Quan, J. C. Corbo, N. D. Finkelstein, A. Pawlak, K. Falkenberg, C. Geanious, C. Ngai, C. Smith, S. Wise, M. E. Pilgrim, et al., Physical Review Physics Education Research 15, 010141 (2019).

[5] C. Bovill, International Journal for Students as Partners 1 (2017).

[6] L. Mercer-Mapstone, S. L. Dvorakova, K. E. Matthews, S. Abbot, B. Cheng, P. Felten, K. Knorr, E. Marquis, R. Shammas, and K. Swaim, International Journal for Students as Partners 1 (2017).

[7] K. E. Matthews, L. Mercer-Mapstone, S. L. Dvorakova, A. Acai, A. Cook-Sather, P. Felten, M. Healey, R. L. Healey, and E. Marquis, International Journal for Academic Development 24, 246 (2019).

[8] C. Ngai, J. Corbo, G. Quan, K. Falkenberg, C. Geanious,
A. Pawlak, M. Pilgrim, D. Reinholz, C. Smith, and S. Wise, Transforming Institutions: Accelerating Systemic Change in Higher Education (2020).

[9] C. Ngai, J. Corbo, K. Falkenberg, C. Geanious, A. Pawlak, M. Pilgrim, G. Quan, D. Reinholz, C. Smith, and S. Wise, Facilitating Change in Higher Education: The Departmental Action Team Model (Glitter Cannon Press, Boulder, CO, 2020).

[10] J. C. Corbo, D. L. Reinholz, M. H. Dancy, S. Deetz, and N. Finkelstein, Physical Review Physics Education Research 12, 010113 (2016).

[11] K. Tobin and W.-M. Roth, School Science and Mathematics 105, 313 (2005).

[12] A. Kezar, How colleges change: Understanding, leading, and enacting change (Routledge, 2018).

[13] K. E. Matthews, A. Cook-Sather, A. Acai, S. L. Dvorakova, P. Felten, E. Marquis, and L. Mercer-Mapstone, Higher Education Research \& Development 38, 280 (2019).

[14] R. A. Engle, F. R. Conant, and J. G. Greeno, Video research in the learning sciences pp. 239-254 (2007).

[15] S. J. Tracy, Qualitative inquiry 16, 837 (2010). 